\title{
Functional and Homeostatic Impact of Age-Related Changes in Lymph Node Stroma
}

\author{
Heather L. Thompson', Megan J. Smithey', Charles D. Surh ${ }^{2,3,4}$ and \\ Janko Nikolich-Žugich ${ }^{1 *}$
}

${ }^{1}$ Department of Immunobiology, The Arizona Center on Aging, University of Arizona College of Medicine, Tucson, AZ, United States, ${ }^{2}$ Academy of Immunology and Microbiology, Institute of Basic Science, Pohang, South Korea, ${ }^{3}$ Department of Integrative Biosciences and Biotechnology, Pohang University of Science and Technology, Pohang, South Korea,

${ }^{4}$ Division of Developmental Immunology, La Jolla Institute of Allergy and Immunology, La Jolla, CA, United States

OPEN ACCESS

Edited by:

Sudhir Gupta,

University of California Irvine,

United States

Reviewed by:

Simona W. Rossi,

University of Basel, Switzerland

Masato Kubo,

Tokyo University of Science, Japan

David Dombrowicz,

Institut national de la santé et de la

recherche médicale (INSERM),

France

Mary A. Markiewicz,

University of Kansas Medical

Center, United States

*Correspondence:

Janko Nikolich-Žugich

nikolich@email.arizona.edu

Specialty section: This article was submitted to Inflammation,

a section of the journal

Frontiers in Immunology

Received: 19 April 2017

Accepted: 31 May 2017

Published: 14 June 2017

Citation:

Thompson HL, Smithey MJ, Surh CD and Nikolich-Žugich J (2017)

Functional and Homeostatic Impact of Age-Related Changes in

Lymph Node Stroma.

Front. Immunol. 8:706.

doi: 10.3389/fimmu.2017.00706
Adults over 65 years of age are more vulnerable to infectious disease and show poor responses to vaccination relative to those under 50. A complex set of age-related changes in the immune system is believed to be largely responsible for these defects. These changes, collectively termed immune senescence, encompass alterations in both the innate and adaptive immune systems, in the microenvironments where immune cells develop or reside, and in soluble factors that guide immune homeostasis and function. While age-related changes in primary lymphoid organs (bone marrow, and, in particular, the thymus, which involutes in the first third of life) have been long appreciated, changes affecting aging secondary lymphoid organs, and, in particular, aging lymph nodes (LNs) have been less well characterized. Over the last 20 years, LN stromal cells have emerged as key players in maintaining LN morphology and immune homeostasis, as well as in coordinating immune responses to pathogens. Here, we review recent progress in understanding the contributions of LN stromal cells to immune senescence. We discuss approaches to understand the mechanisms behind the decline in LN stromal cells and conclude by considering potential strategies to rejuvenate aging LN stroma to improve immune homeostasis, immune responses, and vaccine efficacy in the elderly.

Keywords: aging, immunity, lymph nodes, fibroblastic reticular cells, lymphatic endothelial cells, naïve T cells

\section{INTRODUCTORY REMARKS}

Older adults exhibit a greater susceptibility to infection and reduced responses to vaccination relative to young adults, and infectious diseases remain among the leading causes of morbidity and mortality in the elderly ( $>65$ years of age) (1). While multiple changes occur in the organism with aging, immune senescence is believed to be the key culprit for this susceptibility. Immune senescence affects both the innate and adaptive branches of the immune system, as well as the stromal microenvironments that affect T cell development and homeostasis (2-4). It has been well established that the thymus begins involution relatively early in life, becoming progressively smaller, more disorganized, and functionally inferior, with reduced naïve T cell output (5). The

Abbreviations: BEC, blood endothelial cells; DC, dendritic cell; ECM, extracellular matrix; FDC, follicular dendritic cell; FRC, fibroblastic reticular cell; HEV, high endothelial venule; ILC, innate lymphoid cells; LEC, lymphatic endothelial cell; LN, lymph node; LTi, lymphoid tissue inducer; LTo, lymphoid tissue organizer; SCS, subcapsulary sinus. 
changes in output of naïe $\mathrm{T}$ cells from the aging thymus have long been associated with the numerical decline in naïve $\mathrm{T}$ cells in the periphery of aged animals, while memory T cells accumulate proportionally (4). However, memory cells do not increase in absolute numbers with aging unless persistent infection with cytomegalovirus is also present (6). Substantial research has dissected the changes that occur to both $\mathrm{T}$ cell development with age (5) and to peripheral $\mathrm{T}$ cell homeostasis and function (2). However, less attention has been paid to the aging stromal environment that is expected to maintain these lymphocytes throughout the lifespan. Here, we discuss the series of changes that affect the aging lymph node (LN) architecture and function as a critical factor contributing to poor age-associated immune responses and propose new therapeutic targets to rejuvenate the aging immune system.

\section{FUNCTION AND ORGANIZATION OF LN STROMA}

The primary function of the $\mathrm{LN}$ is to coordinate immune responses to antigens trafficking from peripheral tissues. The non-hematopoietic stromal cell subsets provide the architecture and scaffolding necessary to guide cellular trafficking and compartmentalization, facilitate antigen presentation to circulating naïve $\mathrm{T}$ and $\mathrm{B}$ cells and thereby promote immune surveillance against infection. In addition, LN stromal cells are responsible for the production and presentation of chemokines that coordinate this trafficking of lymphocytes into and throughout the LN $(7,8)$. LN stromal cells also provide a crucial microenvironment for immune homeostasis and lymphocyte maintenance via presentation of pro-survival cytokines such as IL-7 and IL-15 to T cells $(7,8)$, and CXCL13 and B-cell activating factor of the TNF family (BAFF) to B cells (9).

\section{Phenotypic Characteristics of LN Stromal Cells}

The stromal cells of the LN are a numerically small, CD45-TER119population derived from endothelial and mesenchymal progenitors, relative to hematopoietic-derived $\mathrm{CD}_{4} 5^{+}$or TER $119^{+}$cells, which make up the vast majority (>98\%) of LN cells (10) (Ter119 marks red blood cells). Within the stromal fraction, cell surface expression of podoplanin (PDPN, also known as gp38), CD31 (PECAM-1), and CD35/CD21 (complement receptor 1 and 2) distinguish five major, functionally important subsets: fibroblastic reticular cells (FRCs; gp $38^{+} \mathrm{CD} 31^{-} \mathrm{CD} 35 / \mathrm{CD} 21^{-}$), lymphatic endothelial cells (LECs; gp $38^{+} \mathrm{CD} 31^{+} \mathrm{CD} 35 / \mathrm{CD} 21^{-}$), blood endothelial cells (BECs; gp38 $8^{-} \mathrm{CD} 31^{+} \mathrm{CD} 35 / \mathrm{CD} 21^{-}$), follicular dendritic cells (FDCs; gp $38^{ \pm} \mathrm{CD} 31^{-} \mathrm{CD} 35 / \mathrm{CD} 21^{+}$), and double/ triple negative $(\mathrm{DN})$ cells $\left(\mathrm{gp} 38^{-} \mathrm{CD} 31^{-} \mathrm{CD} 35 / \mathrm{CD} 21^{-}\right)(11,12)$ (Figure 1; Table 1).

\section{Functional Characteristics of LN Stromal Subsets}

The endothelial derived LECs and BECs help mediate transport of both circulating cells and tissue-derived antigens into and out of the LNs. Entry into the lymphatics from the tissues occurs through lymphatic collectors and vessels lined with LECs (17). LECs also line sinuses in the LNs delivering antigen from the tissues and providing a route for cells to travel to the next LN (18). In general, BECs line blood vessels. A specialized BEC subset, called HEVs facilitates entry of circulating lymphocytes into the LN via a multistep adhesion and extravasation process utilizing chemokines, selectins, addressin and integrins (18).

Mesenchymal cells create the reticular network within the LN and are critical for the maintenance of its architecture; FRCs, FDCs, and DN stromal cells partake in this task. FRCs are a specialized type of reticular fibroblast that create a large proportion of the stromal network within the LN (19). FRCs ensheath bundles of collagen fibers to create conduits for the transport of small molecules, including antigens/antigen complexes and provide a transport system that guides DC and T cell movement (20). FDCs are also specialized reticular fibroblasts (9) that secrete CXCL13, guiding B cells, and follicular helper $\mathrm{T}$ cells into the germinal center (GC) to facilitate high-affinity antibody production (21). While the function of DN/TN cells is largely unknown, gene profiling studies suggest that some of these cells may be mesenchymal progenitors, consistent with their positioning as pericytes $(20,22)$. Pericytes within the double negative fraction may also help regulate blood vessel integrity, as well as permeability within the LN (22).

\section{Hematopoietic Cells Facilitate LN Stroma Maintenance}

Lymph node stromal cells have close bidirectional relationships with hematopoietic cells, each contributing to the homeostasis of the other (23). Innate lymphoid cells (ILC) are a broad category of cells that develop from common lymphocyte progenitors but do not have rearranged antigen receptors (24). ILC include lymphoid tissue inducers (LTi), which are a sub-group of ILC group 3 cells (25). During LN development, LTi are an important source of lymphotoxin beta (LT $\beta$ ), which combines with lymphotoxin alpha to make the heterotrimer $\operatorname{LT} \alpha_{1} \beta_{2}(25,26)$. This heterotrimer can signal mesenchymal stem cells through the LT $\beta$ receptor (LT $\beta \mathrm{R}$ ) to differentiate into lymphoid tissue organizers, which are critical in inducing proper development and architecture formation of other stromal cells, particularly FRC. Although LTi were originally recognized for their role in $\mathrm{LN}$ developmental, they are present in the adult LN and appear to also mediate adult tissue regeneration (24). LTi help induce regeneration of FRC networks in the spleen and LN following lymphocytic choriomeningitis virus infection (27). It should be noted that while LTi are an important source of LT, other lymphocytes including T, B, and NK cells also secrete LT and contribute to LT availability in the LN (28). Therefore, it is possible, and indeed likely, that naive $\mathrm{T}$ and/or $\mathrm{B}$ cells contribute to the health and maintenance of FRC and other stromal cells, which, in turn, provide trophic factors for naïve lymphocyte survival and maintenance.

Other signals from hematopoietic populations in the LN influence the structure, function, repair, and regeneration of LN stroma. C-type lectin receptor 2 (CLEC-2) is expressed by megakaryocytes, platelets, neutrophils, DCs, and NK cells $(12,29)$. CLEC-2 serves as a ligand for PDPN expressed on 


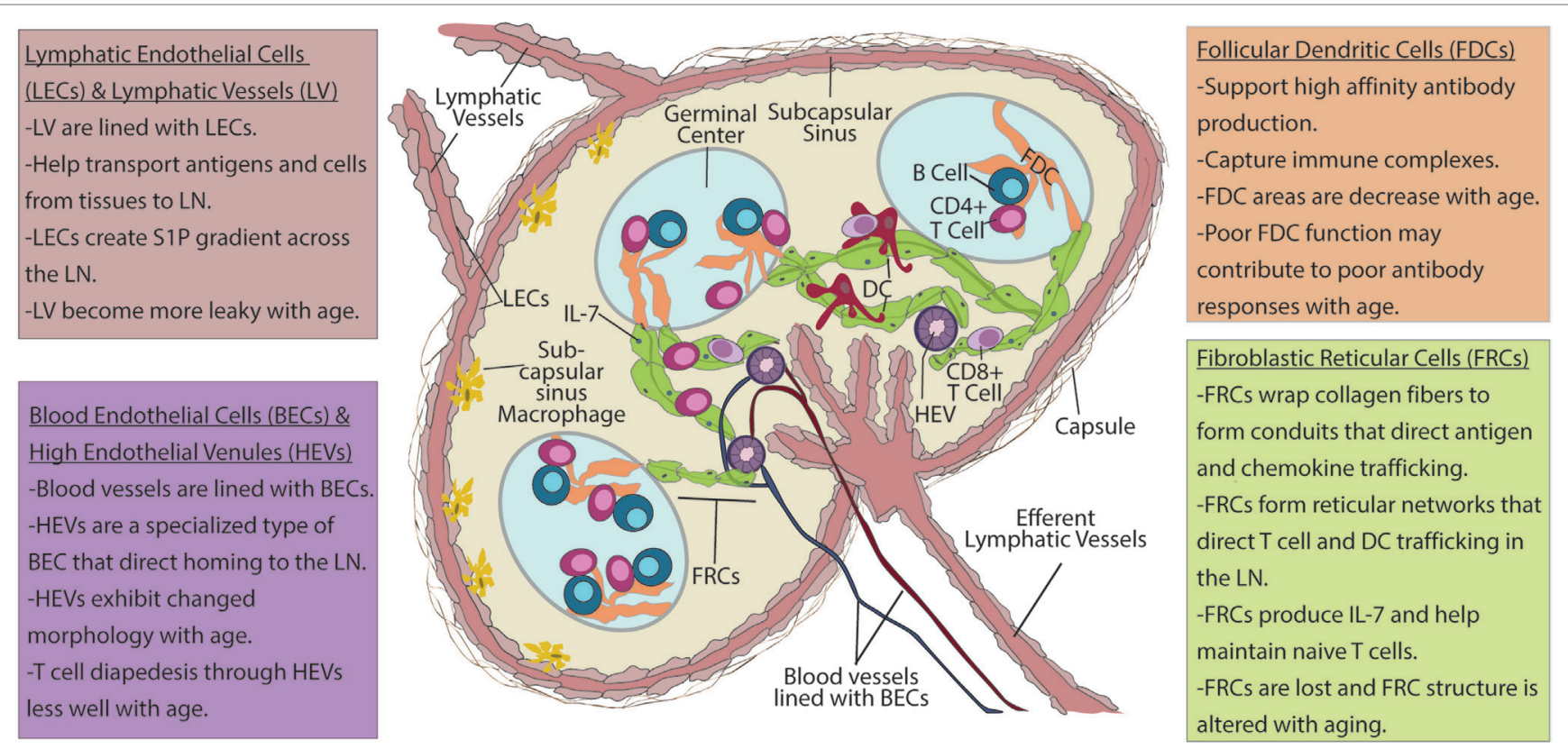

FIGURE 1 | Lymph node (LN) stroma elements and their changes with aging. Upper left box: lymphatic vessels (LVs) are lined with lymphatic endothelial cells (LECS). These vessels transport antigens and cells from peripheral tissues to draining LNs. LECs also produce sphingosine-1-phosphate (S1P) that forms a chemotactic gradient for migration of T cells into efferent lymphatics. Migratory dendritic cells (DCs) enter LN via LVs and into subcapsulary sinuses (SCSs) before entering the LN parenchyma. As antigens drain into the SCS, which are also lined with LECs, SCS macrophages pick up antigen and transfer it to follicular dendritic cells (FDCs). Upper right box: FDCs present immune complexes to B cells to enhance high-affinity antibody formation. Lower left box: blood endothelial cells (BECs) line blood vessels that transport blood borne cells into LN. High endothelial venules (HEVs) are specialized BECs with cuboidal morphology, T cell diapedesis across HEVs to enter the LN parenchyma. Lower right box: after entering the LNs naive T cells from the blood stream crawl along fibroblastic reticular cells (FRCs) that form the reticular network in search of DCs bearing cognate peptide-MHC and costimulation to become activated. FRCs also have critical roles in the maintenance of naïv T cells through the production chemokines and IL-7. Age-related changes: with age, LVs become leaky and less capable of facilitating movement between of cells and antigens between the peripheral tissues and the LN to coordinate immune response. HEVs have altered morphology with age, and T cells have difficulty moving across HEVs with increased age. FRCs exhibit numerical reduction as well as disorganization of reticular networks with aging. This is likely to impair naïve $T$ cell homeostasis, as well as movement of $T$ cells within the $L N$ and may impact the ability of aged $L N$ to generate productive $T$ cell responses. FDC areas are also reduced with age. Changes to FDCs may contribute to poor affinity of antibody responses that are observed with increased age.

stromal cells and triggers the relaxation of FRC networks (30), which in turn impacts how many antigen specific $\mathrm{T}$ cells can be recruited into the LN to respond (31). FRC lines isolated from LN are dependent on lymphocytes for production of ER-TR7 [which identifies the extracellular matrix (ECM) produced by FRC, but the antigen has not been identified]; reticular networks fail to form in the absence of this interaction in vitro $(7,23)$. Therefore, a picture is emerging of intense cross talk between hematopoietic and stromal cells, critical to the homeostasis and function of both compartments in the LN, although many mechanistic details still remain to be defined.

\section{FUNCTIONAL CONSEQUENCES OF AGE-RELATED CHANGES TO LN STROMAL CELLS}

\section{Stromal Cells in Aged LN}

While the contribution of LN stromal cells to both immune homeostasis and function is evident, age-related changes affecting stromal cells have been under investigated (32). Therefore, age-related dysfunction and/or disorganization of LN stromal cells may be an underappreciated contributor to immune senescence. Several groups have described chronic and progressive changes that occur in LN with age (33-35). In general, with aging, LN in both mouse and man become smaller and less cellular (33). Similar to thymic involution, histological studies of LN highlight that the organization is less distinct (especially between $\mathrm{T}$ and $\mathrm{B}$ cell areas) $(13,14)$, with an accumulation of adipocytes (33) and signs of fibrosis (34). Similar disorganization between $\mathrm{T}$ and $\mathrm{B}$ cell areas occurs in the aging spleen (36). It should be noted that not all LNs undergo the same age-related changes; skin-draining LNs are more affected than mucosal LN (33). Below, we discuss key defects in aging LN stroma that have been identified to date.

\section{TRANSPORT IN AND OUT OF LN}

\section{LVs and LECs}

Afferent LV function as conduits for trafficking of both antigens and immune cells. DCs that have captured antigen in tissues move via LVs from peripheral tissues into draining LN (16). Imaging studies demonstrated that aged mice show a diminished capacity to transport bacteria (Cryptococcus neoformans, 
TABLE 1 | Age-related changes to lymph node (LN) stromal cell populations.

\begin{tabular}{|c|c|c|c|}
\hline Cell type & Markers & Known functions & Changes with age \\
\hline $\begin{array}{l}\text { Fibroblastic } \\
\text { reticular cells } \\
\text { (FRCs) }\end{array}$ & $\begin{array}{l}\text { gp38+ }{ }^{+}, \mathrm{CD}^{-} 1^{-} \\
\text {CD35/CD21, CD45-, } \\
\text { Ter119- } \\
\text { ER-TR7+ in histology }\end{array}$ & $\begin{array}{l}\text { - Help form conduits and reticular network } \\
\text { - Regulate naïve T homeostasis } \\
\text { - Regulate naïve T cell movement } \\
\text { - Secrete CCL19, CCL21, and CXCL12 } \\
\text { - IL-7 presentation }\end{array}$ & $\begin{array}{l}\text { - Becklund et al. found that FRCs are decreased in aging LN in } \\
\text { homeostasis (13), while Turner and Mabbott found that FRC } \\
\text { numbers are unchanged (14) } \\
\text { - FRC structure altered (13) }\end{array}$ \\
\hline $\begin{array}{l}\text { Follicular dendritic } \\
\text { cells (FDCs) }\end{array}$ & $\begin{array}{l}\text { CD35/CD21+, } \\
\text { gp38 }{ }^{+/-}, \text {CD31-', } \\
\text { CD45-, Ter119- }\end{array}$ & $\begin{array}{l}\text { - Make reticular network for B cells } \\
\text { - FDC secrete CXCL13 } \\
\text { - Support production of high-affinity antibodies } \\
\text { - Capture immune complex }\end{array}$ & $\begin{array}{l}\text { - FDC area decreased in aged mice (14) } \\
\text { - Less CXCL13 produced in aged mice (protein) (14) } \\
\text { - More CXCL13 expressed in aged mice by qPCR (13) } \\
\text { - Less CXCL13 produced in response to infection in aged } \\
\text { mice (15) }\end{array}$ \\
\hline $\begin{array}{l}\text { Double negative } \\
\text { stromal cells (DN) }\end{array}$ & $\begin{array}{l}\text { gp38-, CD31-' } \\
\text { CD35-, CD45-' } \\
\text { Ter119- }\end{array}$ & $\begin{array}{l}\text { - Thought to be FRC like pericytes } \\
\text { - Function of these cells is mostly unknown }\end{array}$ & - Decreased in number in aged mice (14) \\
\hline $\begin{array}{l}\text { Blood endothelial } \\
\text { cells (BECs) }\end{array}$ & $\begin{array}{l}\text { gp38-, CD31+, } \\
\text { CD35-, CD45- }^{-} \\
\text {Ter119- }\end{array}$ & $\begin{array}{l}\text { - BECs construct cortical blood vessels and capillaries, } \\
\text { including high endothelial venules (HEVs) }\end{array}$ & - Unchanged between old and adult mice (14) \\
\hline HEVs & $\begin{array}{l}\text { These are a } \\
\text { type of BEC } \\
\text { PNAd in histology }\end{array}$ & $\begin{array}{l}\text { - Main route of entry for lymphocytes } \\
\text { - HEVs have cuboidal morphology }\end{array}$ & $\begin{array}{l}\text { - Impaired T cell diapedesis at aged HEV }(13,15) \\
\text { - HEVs reported as more dense and compressed in } \\
\text { aged LN (13) }\end{array}$ \\
\hline $\begin{array}{l}\text { Lymphatic } \\
\text { endothelial } \\
\text { cells (LECS) }\end{array}$ & $\begin{array}{l}\text { gp38+ }{ }^{+}, \mathrm{CD}^{+} 1^{+} \\
\text {CD35-, CD45-, } \\
\text { Ter119- } \\
\text { LYVE-1+ in histology }\end{array}$ & $\begin{array}{l}\text { - Transport antigens and lymph from peripheral tissues } \\
\text { to LN. } \\
\text { - Connection between LN } \\
\text { - Help create sphingosine-1-phosphate gradient } \\
\text { across LN }\end{array}$ & - No change in LECs (14). \\
\hline $\begin{array}{l}\text { Lymphatic vessels } \\
\text { (LVs) }\end{array}$ & LYVE-1+ & $\begin{array}{l}\text { - Transport antigens, immune cells, and lymph from } \\
\text { peripheral tissues to LN }\end{array}$ & $\begin{array}{l}\text { - LV showed a } 20 \% \text { decrease in contraction amplitude and } \\
\text { a } 70 \% \text { decrease in contraction frequency (16) } \\
\text { - LV leakiness and impaired pathogen clearance in aged mice } \\
\text { between footpad and popliteal LN (16) }\end{array}$ \\
\hline
\end{tabular}

Mycobacterium smegmatis, and Staphylococcus aureus) from peripheral tissues into the draining LN, as seen by bacteria leaking out of lymphatics and into the surrounding tissue (16). This was due to both increased LV permeability (an LEC defect) and reduced contractility of the musculature that surrounds the LVs (16). Using paraquat to induce oxidative stress to LECs in a transwell system, the same study found increased LEC permeability to FITC-dextran (16). The authors proposed that the impaired in vivo bacterial transport was caused by increased oxidative stress to LECs (16).

Within the LN, the lymph enters through afferent lymphatics into subcapsulary sinus (SCS) lined with LECs and SCS macrophages (SCSM) (18). LECs provide routes in and out of the LN while the SCSM trap pathogens, antigen, and immune complex as they come into the LN $(14,37)$. Thus, the SCSM network, positioned at the entry of afferent lymphatics, acts to reduce pathogen dissemination and to increase the chance that antigen-presenting cells will come into contact with the rare T cell that might recognize them (37). SCSM additionally transfer incoming immune complexes to non-cognate B cells, which then transfer the complexes to FDCs (38). FDCs shuttle these antigens into non-degradative endosomal compartments, allowing longterm retention and presentation of the antigens (38). Turner and Mabbott showed that aged mice exhibit a significant increase in SCSM as a fraction of hematopoietic cells (14). Despite this increase in SCSM, the FDCs in aged mice fail to retain immune complexes (14). Further research is needed to address whether in old mice this increased SCSM population fails to efficiently capture/handoff antigen to FDCs, or whether these antigens are being shuttled into degradative endosomes, rather than the usual non-degradative endosomes that allows immune complexes to be retained by FDCs.

\section{BECs and HEVs}

Circulating naïve B and T cells enter the LN through HEVs, which are a specialized subtype of BEC (18). HEVs have a cuboidal shape and a polarized expression of adhesion molecules so that circulating cells in the blood can anchor to the HEVs and extravasate into the LN (39). BECs (including HEVs) appear to be unchanged numerically in aged mice (14); however, aged HEVs appear to have a more dense and compressed morphology (13). There is some evidence that aged BECs show changes similar to that of the aging vascular system, including increased permeability, inflammation, and number of senescent endothelial cells $(32,40)$. Moreover, aged HEVs may poorly facilitate lymphocyte entry into the aged LN, based on experiments showing pronounced defects in recruiting adoptively transferred adult naïve $\mathrm{T}$ cells into old LN $(13,15)$.

\section{CELLS OF THE RETICULAR NETWORK}

The reticular network provides the structure and architecture of the LN (23). The reticular network is composed of reticular 
fibers, ECM, and mesenchymal lineage cells such as FRCs and FDCs. Collectively, the reticular network creates specific microanatomical sites within the LNs that support and coordinate immune cells through the production of cytokines and chemokines (41).

\section{Fibroblastic Reticular Cells}

Fibroblastic reticular cells are a category of cells representing at least five different populations (10). FRCs are uniquely important in both organizing the $\mathrm{T}$ cell zone within the LN and in maintaining naïve $\mathrm{T}$ cell viability and function. The conduits formed by FRCs extend across the T cell zone from the SCS to the HEVs and construct the reticular network of the LN (37). FRCs are specialized myofibroblast (10) that, like other myofibroblasts, express $\alpha$-smooth muscle actin (7). Unlike other myofibroblasts, FRCs ensheath ECM-like collagen bundles, whereas fibroblasts in connective tissues are embedded within the ECM (23). Also, FRCs have higher expression of genes involved in cytokine signaling, as well as genes involved in antigen presentation pathways (42). FRCs can directly present antigens to promote either $\mathrm{T}$ cell activation or $\mathrm{T}$ cell peripheral tolerance (37). FRC expression of chemokines CCL21 and CCL19 controls T cell motility. It has been proposed that CCL21 interacts in a unique manner with glycosaminoglycans on FRCs to facilitate T cell movements (37). Specifically, CCL21 has a 32 amino acid long C-terminal tail containing 12 basic amino acid residues. This allows it to bind to glycosaminoglycans and other molecules like PDPN, a proteoglycan expressed by LECs and FRCs (43).

Naïve T cells decline in number with age (2). This has been primarily attributed to age-related thymic involution and the consequent decline in new naïve $\mathrm{T}$ cells produced. However, naïve $\mathrm{T}$ cells can have a long lifespan if provided the appropriate survival signals $(7,44)$. Link et al. demonstrated that FRCs play a key role in naïve $\mathrm{T}$ cell survival via production and presentation of IL-7 and CCL19 (7). Genetic knockout or antibody-mediated depletion of IL-7 results in a gradual loss of peripheral naïve T cells, whereas IL-7 transgenic mice exhibit a larger naïve T cell pool (45). Bajénoff et al. used intravital microscopy to show that T cells enter the LN via HEVs, then use FRCs to crawl to the LN parenchyma (19). When FRCs are depleted [e.g., in CCL19diphteria-toxin (CCL19-DTR) mice], the total cellularity of the LN declines, with a significant loss of T cells beginning $24 \mathrm{~h}$ after FRC depletion (46).

Becklund et al. extended these findings testing whether LN in old mice can support adult $\mathrm{T}$ cell homeostasis. Both naïve TCRtransgenic and polyclonal populations from adult donors failed to survive, and proliferated less in old LN compared to adult LN after transfer (13). Further, old LN exhibited reduced numbers of FRCs, and their reticular network appeared less reticular and more condensed than in adults (13). Despite possessing normal levels of IL-7 mRNA in LN and IL-7 protein in circulation in old individuals, naïve $\mathrm{T}$ cells parked in old hosts exhibited lower levels of phosphorylated signal transducer and activator of transcription 5, a signaling molecule downstream of IL-7R (13). The discrepancy between the levels of IL-7 and the homeostatic signals received by naive $\mathrm{T}$ cells suggested that IL-7 presentation by FRCs is altered in aged microenvironments. Mechanistic understanding of the naïve $\mathrm{T}$ cell maintenance programs across aging and across species (47) will be exceptionally important to immune rejuvenation strategies.

In addition to these problems of homeostatic maintenance, aged FRCs likely also contribute to the compromised immune responses to infection. An adult $\mathrm{LN}$ can expand up to 10 -fold during an infection (48). Old LNs expand modestly, but never reach the cellularity seen during an adult immune response $(15,49)$. During infection, chemokines and cytokines are transported through FRC networks to HEVs where they are transcytosed and displayed on the luminal side of HEVs to recruit naïve $\mathrm{T}$ cells (50). Antigen-bearing DCs crawl first through LV into LN through afferent lymphatics, then along FRCs in search of their cognate T cell. Loss of LN organization and boundaries between $\mathrm{B}$ and $\mathrm{T}$ cell zones make the host more susceptible to infection (50). Depletion of FRC in adult CCR19-DTR mice resulted in reduced responses to replication incompetent influenza A or to a coronavirus-based vector, likely due to the reduction in chemokines reaching $\mathrm{HEV}$ s to recruit lymphocytes into the $\mathrm{LN}$, and/or a reduction in coordination of immune cells within the LN (46). Somewhat unexpectedly, FRC depletion also had a profound negative impact on both B cell homeostasis (reduced B cell follicle size and disrupted $\mathrm{T} / \mathrm{B}$ boundary), and decreased $\mathrm{T}$-dependent and $\mathrm{T}$-independent antibody responses.

Fibroblastic reticular cells are also a key source of collagen in the LN. Appropriate thickness and abundance of collagen, which is essential as part of the ECM, is an important physiological parameter of organ architecture and function (51). Increased thickness and abundance of collagen fibers, termed fibrosis, is a frequent change to many organs during aging and is associated with impaired function (52). Wound-healing cytokines, dominantly TGF $\beta$ and type 2 cytokines like IL-13 (53), induce fibrosis in $\mathrm{LN}$ and other organs and are also known to be increased with aging $(52,54)$. This process is believed to operate via FRC in some pathogenic conditions $(55,56)$ and is likely to also occur in the same manner during aging.

\section{Follicular Dendritic Cells}

Follicular dendritic cells are specialized cells of mesenchymal origin $(10,57)$, named for their long cytoplasmic "dendritic" processes and are unrelated to classical hematopoietic DC $(58,59)$. The role of FDCs during homeostasis is less clear, but during infection FDCs support B cell movement and proper localization to GCs by producing CXCL13, as well as B-cell activating factor of the TNF family (BAFF) and a proliferationinducing ligand (50). FDCs additionally help generate highaffinity antibody responses (10) by allowing prolonged antigen presentation to B cells undergoing somatic hypermutation (38).

Defects in FRCs and FDCs are a potential factor underlying poor humoral immunity in the elderly. Antibody responses are of lower affinity and impaired function compared to young adults (60). For example, during chikungunya virus infection, high antibody titers are found in old mice, but they show poor neutralizing function compared to adults (49). Further, aging results in fewer B cells within the LN (49), and B cell localization is less 
defined $(13,14)$. GC formation is reduced in the LN of aged mice infected with West Nile virus relative to adult controls (15). GC size has also been reported to decline with age in humans (33). FDCs are responsible for coordinating these events but have a decreased area in LN of aged mice compared to their adult counterparts (14), and less CXCL13 protein is produced in response to infection and in homeostasis $(14,15)$. Turner and Mabbott also found that immune complexes were retained less by aged FDCs (14). This loss of antigen may suggest that a degradative endocytic pathway is being used by aged FDCs, although this has not been directly demonstrated. These observations are consistent with the idea that age-associated impairments in FDCs (14) are a contributing factor to poor antigen retention, impaired GC formation, and decline in the production of high-affinity, functionally neutralizing antibodies.

\section{MECHANISMS BEHIND LN INVOLUTION AND REJUVENATION}

\section{Understanding the Mechanisms behind LN Involution}

As mentioned above, the mechanisms driving LN changes with aging remain incompletely understood. Heterochronic parabiosis, the surgical joining of two organisms of different ages (adult and old) $(3,61)$, can be a powerful tool to discern cell-intrinsic vs. to cell-extrinsic (environmental) defects that occur with age (3). Both pro-geronic (62) and anti-geronic (63) factors have been identified using this technique. Using heterochronic parabiosis, we found a surprisingly marked loss of naïve T cell maintenance in the LN of the adult parabiont, with numbers reduced to that in the old parabiont (64). After surgical separation of the parabiosed adult and old mice, the adult LN returned to normal, while the old remained hypocellular. While joined, the frequencies and numbers of stromal subsets in the adult parabiont were similar to the old parabiont than to those in isochronic parabiosis (adult-adult pairs). Together, these results suggest that a circulating soluble or cellular factor, present in the old parabiont, can influence the structure and cellularity of the adult LN in trans. Research is in progress to test this hypothesis.

\section{Possible Molecular Targets to Rejuvenate Aging LN}

Based on the observed defects, discussed above, one can hypothesize about candidate molecular pathways responsible for LN defects. One attractive target is LT signaling. The receptor for LT $\beta$ (LT $\beta$ R) is expressed on LECs, HEVs, FRCs, and FDCs $(28,39)$. The bidirectional relationship between $\mathrm{T}$ cells and FRCs in homeostasis is critical for both populations of cells (23). Known producers of LT, such as DCs, B cells, and T cells (37) are less abundant in the aged LN $(15,49)$. When LT $\beta$ is conditionally depleted in young mice, there is a decline in LN organization and impaired induction of antiviral immune responses (37), similar to that described in aged $\mathrm{LN}(14,15)$.
Approaches that limit fibrosis should also be considered. Regardless of tissue type, aging is the biggest risk factor for fibrosis (52), including in skin-draining $\operatorname{LN}$ in humans $(34,35)$. Serum levels of transforming growth factor-beta (TGF- $\beta$ ) are increased with aging in both mice and humans (65) and may be related to the age-associated increases in T-regulatory cells $(10,53,66)$. Within the LN, fibrosis has been most studied in the context of simian immunodeficiency virus (SIV) in nonhuman primates (55). Increased levels of TGF- $\beta$, pSMAD2,3 signaling, and increased levels of fibrosis were found in LN of SIV-infected animals, where immune reconstitution is limited after antiretroviral therapy (55). As SIV infection proceeds, naïve $\mathrm{T}$ cells in fibrotic regions undergo apoptosis $(10,67)$. Administration of the anti-fibrotic drug pirfenidone to reverse fibrosis restored naïve $\mathrm{CD} 4^{+} \mathrm{T}$ cell populations in SIV-infected monkeys in combination with antiretroviral therapy (55). Along these lines, we have observed increased fibrosis in aged mouse LN compared to adults. Understanding the interactions between FRCs and lymphocytes, and how fibrosis may impact these communications could have important therapeutic potential (10).

\section{CONCLUSION}

Age-related changes to LN stroma are emerging as an important area of research. Full understanding of these changes will likely be critical to understand, and, perhaps, correct age-related disorganization of $\mathrm{T}$ cell homeostasis and immune function. LN stroma is critical for naïve $\mathrm{T}$ cell homeostasis, providing both chemokine gradients for effective trafficking into the LN, and survival signals to the naïve $\mathrm{T}$ cell upon arrival $(7,13)$. Further, stromal cells control influx of antigen, and there is initial evidence that this process may be adversely affected by aging LN $(15,16)$. Within the LN, FRCs (13) and FDCs (14), both decline numerically and exhibit disorganized network formation, with a potential to impair interactions with $\mathrm{T}$ and $\mathrm{B}$ cells. A key challenge in front of us is to (1) understand how aging alters the structure and function of each of the stromal cellular components and their interaction and (2) dissect the functional consequences of such changes for protective immunity. The ultimate goal should be to manipulate and restore stromal cell function in response to vaccination or infection and thus provide new targets to improve immunity in the elderly.

\section{AUTHOR CONTRIBUTIONS}

HT, MS, and JN-Z wrote the paper. CS contributed to critically revising the paper. All the authors extensively discussed the topic, read and approved the final version of the manuscript.

\section{FUNDING}

This study was funded by NIAID contract N01-A1-000017 to JN-Z and NIA RO1 AG048021 to JN-Z. 


\section{REFERENCES}

1. Briceño O, Lissina A, Wanke K, Afonso G, Braun von A, Ragon $K$, et al. Reduced naïve CD8(+) T-cell priming efficacy in elderly adults. Aging Cell (2016) 15:14-21. doi:10.1111/acel.12384

2. Nikolich-Žugich J. Aging of the T cell compartment in mice and humans: from no naive expectations to foggy memories. J Immunol (2014) 193:2622-9. doi:10.4049/jimmunol.1401174

3. Nikolich-Žugich J, Davies JS. Homeostatic migration and distribution of innate immune cells in primary and secondary lymphoid organs with aging. Clin Exp Immunol (2016) 187:337-44. doi:10.111./cei.12920

4. Nikolich-Žugich J, Li G, Uhrlaub JL, Renkema KR, Smithey MJ. Age-related changes in CD8 T cell homeostasis and immunity to infection. Semin Immunol (2012) 24:356-64. doi:10.1016/j.smim.2012.04.009

5. Chinn IK, Blackburn CC, Manley NR, Sempowski GD. Changes in primary lymphoid organs with aging. Semin Immunol (2012) 24:309-20. doi:10.1016/j. smim.2012.04.005

6. Wertheimer AM, Bennett MS, Park B, Uhrlaub JL, Martinez C, Pulko V, et al. Aging and cytomegalovirus infection differentially and jointly affect distinct circulating T cell subsets in humans. J Immunol (2014) 192:2143-55. doi:10.4049/jimmunol.1301721

7. Link A, Vogt TK, Favre S, Britschgi MR, Acha-Orbea H, Hinz B, et al. Fibroblastic reticular cells in lymph nodes regulate the homeostasis of naive T cells. Nat Immunol (2007) 8:1255-65. doi:10.1038/ni1513

8. Bajénoff M, Egen JG, Qi H, Huang AYC, Castellino F, Germain RN. Highways, byways and breadcrumbs: directing lymphocyte traffic in the lymph node. Trends Immunol (2007) 28:346-52. doi:10.1016/j.it.2007. 06.005

9. Bajénoff M, Germain RN. B-cell follicle development remodels the conduit system and allows soluble antigen delivery to follicular dendritic cells. Blood (2009) 114:4989-97. doi:10.1182/blood-2009-06-229567

10. Fletcher AL, Acton SE, Knoblich K. Lymph node fibroblastic reticular cells in health and disease. Nat Rev Immunol (2015) 15:350-61. doi:10.1038/ nri3846

11. Fletcher AL, Malhotra D, Acton SE, Lukacs-Kornek V, Bellemare-Pelletier A, Curry M, et al. Reproducible isolation of lymph node stromal cells reveals site-dependent differences in fibroblastic reticular cells. Front Immunol (2011) 2:35. doi:10.3389/fimmu.2011.00035

12. Benezech C, Nayar S, Finney BA, Withers DR, Lowe K, Desanti GE, et al. CLEC-2 is required for development and maintenance of lymph nodes. Blood (2014) 123:3200-7. doi:10.1182/blood-2013-03-489286

13. Becklund BR, Purton JF, Ramsey C, Favre S, Vogt TK, Martin CE, et al. The aged lymphoid tissue environment fails to support naïve $\mathrm{T}$ cell homeostasis. Sci Rep (2016) 6:30842. doi:10.1038/srep30842

14. Turner VM, Mabbott NA. Structural and functional changes to lymph nodes in ageing mice. Immunology (2017) 151(2):239-47. doi:10.1111/imm.12727

15. Richner JM, Gmyrek GB, Govero J, Tu Y, van der Windt GJW, Metcalf TU, et al. Age-dependent cell trafficking defects in draining lymph nodes impair adaptive immunity and control of West Nile virus infection. PLoS Pathog (2015) 11:e1005027. doi:10.1371/journal.ppat.1005027

16. Zolla V, Nizamutdinova IT, Scharf B, Clement CC, Maejima D, Akl T, et al. Aging-related anatomical and biochemical changes in lymphatic collectors impair lymph transport, fluid homeostasis, and pathogen clearance. Aging Cell (2015) 14:582-94. doi:10.1111/acel.12330

17. Aebischer $\mathrm{D}$, Iolyeva $\mathrm{M}$, Halin $\mathrm{C}$. The inflammatory response of lymphatic endothelium. Angiogenesis (2013) 17:383-93. doi:10.1007/s10456-013-9404-3

18. Girard J-P, Moussion C, Förster R. HEVs, lymphatics and homeostatic immune cell trafficking in lymph nodes. Nat Rev Immunol (2012) 12:762-73. doi:10.1038/nri3298

19. Bajénoff M, Egen JG, Koo LY, Laugier JP, Brau F, Glaichenhaus N, et al. Stromal cell networks regulate lymphocyte entry, migration, and territoriality in lymph nodes. Immunity (2006) 25:989-1001. doi:10.1016/j.immuni. 2006.10.011

20. Malhotra D, Astarita J, Lukacs-Kornek V, Tayalia P, Gonzalez SF, Chang SK, et al. Transcriptional profiling of stroma from inflamed and resting lymph nodes defines immunological hallmarks. Nat Immunol (2012) 13:499-510. doi:10.1038/ni.2262

21. Heesters BA, Myers RC, Carroll MC. Follicular dendritic cells: dynamic antigen libraries. Nat Rev Immunol (2014) 14:495-504. doi:10.1038/nri3689
22. Sá da Bandeira D, Casamitjana J, Crisan M. Pericytes, integral components of adult hematopoietic stem cell niches. Pharmacol Ther (2017) 171:104-13. doi:10.1016/j.pharmthera.2016.11.006

23. Katakai T, Hara T, Sugai M, Gonda H, Shimizu A. Lymph node fibroblastic reticular cells construct the stromal reticulum via contact with lymphocytes. J Exp Med (2004) 200:783-95. doi:10.1084/jem.20040254

24. Bar-Ephraïm YE, Mebius RE. Innate lymphoid cells in secondary lymphoid organs. Immunol Rev (2016) 271:185-99. doi:10.1111/imr.12407

25. Artis D, Spits H. The biology of innate lymphoid cells. Nature (2015) 517:293-301. doi:10.1038/nature14189

26. Cupedo T, Kraal G, Mebius RE. The role of CD45+CD4+CD3- cells in lymphoid organ development. Immunol Rev (2002) 189:41-50. doi:10.1034/j.1600-065X.2002.18905.x

27. Scandella E, Bolinger B, Lattmann E, Miller S, Favre S, Littman DR, et al. Restoration of lymphoid organ integrity through the interaction of lymphoid tissue-inducer cells with stroma of the T cell zone. Nat Immunol (2008) 9:667-75. doi:10.1038/ni.1605

28. Zhu M, Fu Y-X. The role of core TNF/LIGHT family members in lymph node homeostasis and remodeling. Immunol Rev (2011) 244:75-84. doi:10.1111/ j.1600-065X.2011.01061.x

29. Acton SE, Astarita JL, Malhotra D, Lukacs-Kornek V, Franz B, Hess PR, et al. Podoplanin-rich stromal networks induce dendritic cell motility via activation of the C-type lectin receptor CLEC-2. Immunity (2012) 37:276-89. doi:10.1016/j.immuni.2012.05.022

30. Acton SE, Farrugia AJ, Astarita JL, Mourão-Sá D, Jenkins RP, Nye E, et al. Dendritic cells control fibroblastic reticular network tension and lymph node expansion. Nature (2014) 514:498-502. doi:10.1038/nature13814

31. Astarita JL, Cremasco V, Fu J, Darnell MC, Peck JR, Nieves-Bonilla JM, et al. The CLEC-2-podoplanin axis controls the contractility of fibroblastic reticular cells and lymph node microarchitecture. Nat Immunol (2015) 16:75-84. doi:10.1038/ni.3035

32. Masters AR, Haynes L, Su DM, Palmer DB. Immune senescence: significance of the stromal microenvironment. Clin Exp Immunol (2016) 187:6-15. doi:10.1111/cei.12851

33. Luscieti P, Hubschmid T, Cottier H, Hess MW, Sobin LH. Human lymph node morphology as a function of age and site. J Clin Pathol (1980) 33:454-61. doi:10.1136/jcp.33.5.454

34. Denz FA. Age changes in lymph nodes. J Pathol Bacteriol (1947) 59:575-91. doi:10.1002/path.1700590409

35. Maiborodin IV, Agzaev MK, Ragimova TM, Maiborodin II. Age-related changes in the structure of lymphoid organs: a review of the literature. $A d v$ Gerontol (2016) 6:282-90. doi:10.1134/S2079057016040081

36. Aw D, Hilliard L, Nishikawa Y, Cadman ET, Lawrence RA, Palmer DB. Disorganization of the splenic microanatomy in ageing mice. Immunology (2016) 148:92-101. doi:10.1111/imm.12590

37. Junt T, Scandella E, Ludewig B. Form follows function: lymphoid tissue microarchitecture in antimicrobial immune defence. Nat Rev Immunol (2008) 8:764-75. doi:10.1038/nri2414

38. Heesters BA, Chatterjee P, Kim Y-A, Gonzalez SF, Kuligowski MP, Kirchhausen T, et al. Endocytosis and recycling of immune complexes by follicular dendritic cells enhances B cell antigen binding and activation. Immunity (2013) 38:1164-75. doi:10.1016/j.immuni.2013.02.023

39. Onder L, Danuser R, Scandella E, Firner S, Chai Q, Hehlgans T, et al. Endothelial cell-specific lymphotoxin- $\beta$ receptor signaling is critical for lymph node and high endothelial venule formation. J Exp Med (2013) 210:465-73. doi:10.1084/jem.20121462

40. Donato AJ, Morgan RG, Walker AE, Lesniewski LA. Cellular and molecular biology of aging endothelial cells. J Mol Cell Cardiol (2015) 89:122-35. doi:10.1016/j.yjmcc.2015.01.021

41. Katakai T, Hara T, Lee J-H, Gonda H, Sugai M, Shimizu A. A novel reticular stromal structure in lymph node cortex: an immuno-platform for interactions among dendritic cells, T cells and B cells. Int Immunol (2004) 16:1133-42. doi:10.1093/intimm/dxh113

42. Malhotra D, Fletcher AL, Turley SJ. Stromal and hematopoietic cells in secondary lymphoid organs: partners in immunity. Immunol Rev (2013) 251:160-76. doi:10.1111/imr.12023

43. Förster R, Davalos-Misslitz AC, Rot A. CCR7 and its ligands: balancing immunity and tolerance. Nat Rev Immunol (2008) 8:362-71. doi:10.1038/ nri2297 
44. Tan JT, Dudl E, LeRoy E, Murray R, Sprent J, Weinberg KI, et al. IL-7 is critical for homeostatic proliferation and survival of naive T cells. Proc Natl Acad Sci U S A (2001) 98:8732-7. doi:10.1073/pnas.161126098

45. Surh CD, Sprent J. Homeostasis of naive and memory T cells. Immunity (2008) 29:848-62. doi:10.1016/j.immuni.2008.11.002

46. Cremasco V, Woodruff MC, Onder L, Cupovic J, Nieves-Bonilla JM, Schildberg FA, et al. B cell homeostasis and follicle confines are governed by fibroblastic reticular cells. Nat Immunol (2014) 15:973-81. doi:10.1038/ ni. 2965

47. den Braber I, Mugwagwa T, Vrisekoop N, Westera L, Mögling R, de Boer $\mathrm{AB}$, et al. Maintenance of peripheral naive $\mathrm{T}$ cells is sustained by thymus output in mice but not humans. Immunity (2012) 36:288-97. doi:10.1016/j.immuni.2012.02.006

48. Textor J, Mandl JN, de Boer RJ. The reticular cell network: a robust backbone for immune responses. PLoS Biol (2016) 14:e2000827. doi:10.1371/journal. pbio. 2000827

49. Uhrlaub JL, Pulko V, DeFilippis VR, Broeckel R, Streblow DN, Coleman GD, et al. Dysregulated TGF- $\beta$ production underlies the age-related vulnerability to Chikungunya virus. PLoS Pathog (2016) 12:e1005891. doi:10.1371/journal. ppat.1005891

50. Chang JE, Turley SJ. Stromal infrastructure of the lymph node and coordination of immunity. Trends Immunol (2015) 36:30-9. doi:10.1016/j.it.2014. 11.003

51. Shoulders MD, Raines RT. Collagen structure and stability. Annu Rev Biochem (2009) 78:929-58. doi:10.1146/annurev.biochem.77.032207.120833

52. Thannickal VJ, Zhou Y, Gaggar A, Duncan SR. Fibrosis: ultimate and proximate causes. J Clin Invest (2014) 124:4673-7. doi:10.1172/JCI74368

53. Borthwick LA, Wynn TA. IL-13 and TGF- $\beta 1$ : core mediators of fibrosis. Curr Pathobiol Rep (2015) 3:273-82. doi:10.1007/s40139-015-0091-1

54. Ahmadi O, McCall JL, Stringer MD. Does senescence affect lymph node number and morphology? A systematic review. ANZ J Surg (2013) 83:612-8. doi:10.1111/ans.12067

55. Estes JD, Reilly C, Trubey CM, Fletcher CV, Cory TJ, Michael Piatak J, et al. Antifibrotic therapy in simian immunodeficiency virus infection preserves CD4+ T-cell populations and improves immune reconstitution with antiretroviral therapy. J Infect Dis (2015) 211:744-54. doi:10.1093/infdis/ jiu519

56. Zeng M, Smith AJ, Wietgrefe SW, Southern PJ, Schacker TW, Reilly CS, et al. Cumulative mechanisms of lymphoid tissue fibrosis and $\mathrm{T}$ cell depletion in HIV-1 and SIV infections. J Clin Invest (2011) 121:998-1008. doi:10.1172/ JCI45157

57. Jarjour M, Jorquera A, Mondor I, Wienert S, Narang P, Coles MC, et al. Fate mapping reveals origin and dynamics of lymph node follicular dendritic cells. J Exp Med (2014) 211:1109-22. doi:10.1084/jem.20132409
58. Kranich J, Krautler NJ. How follicular dendritic cells shape the B-cell antigenome. Front Immunol (2016) 7:225. doi:10.3389/fimmu.2016.00225

59. Chen LL, Adams JC, Steinman RM. Anatomy of germinal centers in mouse spleen, with special reference to "follicular dendritic cells.. J Cell Biol (1978) 77:148-64. doi:10.1083/jcb.77.1.148

60. Pinti M, Appay V, Campisi J, Frasca D, Fülöp T, Sauce D, et al. Aging of the immune system - focus on inflammation and vaccination. Eur J Immunol (2016) 46:2286-301. doi:10.1002/eji.201546178

61. Conboy MJ, Conboy IM, Rando TA. Heterochronic parabiosis: historical perspective and methodological considerations for studies of aging and longevity. Aging Cell (2013) 12:525-30. doi:10.1111/acel.12065

62. Smith LK, He Y, Park J-S, Bieri G, Snethlage CE, Lin K, et al. $\beta 2$-microglobulin is a systemic pro-aging factor that impairs cognitive function and neurogenesis. Nat Med (2015) 21:932-7. doi:10.1038/nm.3898

63. Villeda SA, Plambeck KE, Middeldorp J, Castellano JM, Mosher KI, Luo J, et al. Young blood reverses age-related impairments in cognitive function and synaptic plasticity in mice. Nat Med (2014) 20:659-63. doi:10.1038/ nm.3569

64. Davies JS, Thompson HL, Pulko V, Padilla-Torres J, Nikolich-Zugich J. Role of cell-intrinsic and environmental age-related changes in altered maintenance of murine T cells in lymphoid organs. J Gerontol A Biol Sci Med Sci (2017):glx102. doi:10.1093/gerona/glx102

65. Carlson ME, Conboy MJ, Hsu M, Barchas L, Jeong J, Agrawal A, et al. Relative roles of TGF- $\beta 1$ and Wnt in the systemic regulation and aging of satellite cell responses. Aging Cell (2009) 8:676-89. doi:10.1111/j.1474-9726. 2009.00517.x

66. Garg SK, Delaney C, Toubai T, Ghosh A, Reddy P, Banerjee R, et al. Aging is associated with increased regulatory T-cell function. Aging Cell (2014) 13:441-8. doi:10.1111/acel.12191

67. Zeng M, Paiardini M, Engram JC, Beilman GJ, Chipman JG, Schacker TW, et al. Critical role of CD4 $\mathrm{T}$ cells in maintaining lymphoid tissue structure for immune cell homeostasis and reconstitution. Blood (2012) 120:1856-67. doi:10.1182/blood-2012-03-4186

Conflict of Interest Statement: The authors declare no conflicts of interest. JN-Z is an unpaid Scientific Advisory Board member of Organic Vaccines, Inc., an entity that had no input into any part of studies reported here.

Copyright (C) 2017 Thompson, Smithey, Surh and Nikolich-Žugich. This is an open-access article distributed under the terms of the Creative Commons Attribution License (CC BY). The use, distribution or reproduction in other forums is permitted, provided the original author(s) or licensor are credited and that the original publication in this journal is cited, in accordance with accepted academic practice. No use, distribution or reproduction is permitted which does not comply with these terms. 